\title{
Metodologias Ativas e Aprendizagem Significativa: Processo Educativo no Ensino em Saúde
}

\section{Active Methodologies and Meaningful Learning: Educational Process in Health Education}

\author{
Jackeline Camargos Pereira*a; Luma Ravena Soares Monte; Caroline Cordeiro Souto ${ }^{\mathrm{a}}$; Antonio Henrique Matos ${ }^{\mathrm{b}}$; \\ Rogério Dias Renovato ${ }^{\mathrm{a}}$; Cibele de Moura Sales ${ }^{\mathrm{a}}$; Luzimeire dos Santos Teixeira ${ }^{\mathrm{c}}$
}

\author{
a'Universidade Estadual do Mato Grosso do Sul, Programa de Pós-Graduação Stricto Sensu em Ensino em Saúde. MS, Brasil. \\ bUnidade de Pronto Atendimento Dr. Afrânio Martins. MS, Brasil. \\ 'Secretaria Municipal de Saúde. MS, Brasil. \\ *E-mail: camargosjackeline@gmail.com
}

\begin{abstract}
Resumo
O termo ensino e aprendizagem valoriza a interdependência dos processos de ensinar e de aprender. As metodologias ativas de ensino e a teoria da aprendizagem significativa de Ausubel dão protagonismo ao estudante em seu desenvolvimento cognitivo, respeitando os saberes prévios, teóricos e práticos. O objetivo da pesquisa é analisar uma prática educativa, segundo a teoria da aprendizagem significativa, sobre metodologias ativas no ensino em saúde, realizada no Programa de Pós-graduação em Ensino em Saúde, mestrado profissional, da Universidade Estadual de Mato Grosso do Sul. A prática educativa foi realizada em quatro momentos: construção de uma colcha de retalhos pelos participantes; problematização sobre metodologia ativa; construção de mapa conceitual; e apresentação da teoria da aprendizagem significativa por meio de um cordel elaborado pelo grupo. A confecção da colcha de retalhos resgatou os saberes, bem como propiciou troca de experiências e de reflexões. A problematização desencadeou um consenso de que as metodologias de ensino devem ser estrategicamente planejadas, considerando o contexto e os atores envolvidos. O mapa conceitual como estratégia educativa e de avaliação formativa evidenciou que os mestrandos desenvolveram a aprendizagem significativa na temática abordada. A entoação do cordel sobre a teoria da aprendizagem significativa despertou o interesse e a atenção dos educandos. A prática educativa mobilizou subsunçores na temática, com problematização, reflexão e ressignificação, tanto nos participantes quanto nos mediadores, de forma horizontal no ensino e aprendizagem, em que quem ensina aprende, e quem aprende também ensina. Portanto, foi um processo de metodologia ativa de ensino com aprendizagem significativa.
\end{abstract}

Palavras-chave: Educação em Saúde. Metodologias Ativas de Ensino e Aprendizagem. Problematização. Mapas Conceituais.

\begin{abstract}
The term teaching-learning values the teaching and learning interdependence processes. The active teaching methodologies and Ausubel's theory of meaningful learning provide the student with a leading role in his or her cognitive development, respecting previous, theoretical and practical knowledge. The objective of this research is to analyze an educational practice, according to the theory of meaningful learning, about active methodologies in health education, held in the professional master degree level at University of Mato Grosso do Sul in Health Education Postgraduate Program. The educational practice was performed in 4 moments: a quilt construction by the participants; questioning about active methodology; concept map construction; and presentation of the theory of meaningful learning through a cordel elaborated by the group. The making of the quilt rescued the knowledge as well as provided exchange of experiences and considerations. The questioning triggered a consensus that teaching methodologies should be strategically planned, considering the context and the actors involved. The concept map as an educational strategy and formative evaluation showed that the master degree students developed significant learning in the thematic approach. The cordel intonation about the theory of meaningful learning aroused the students' interest and attention. The educational practice mobilized subsumers, with problematization, reflection and resignification, both in the participants and the mediators, horizontally in teaching-learning, where those who teach learn, and those who learn also teach. Therefore, it was a process of active teaching methodology with significant learning.
\end{abstract}

Keywords: Health Education. Active Teaching-Learning Methodologies. Problematization. Concept Maps.

\section{Introdução}

O termo ensino e aprendizagem valoriza a interdependência entre os processos de ensinar e de aprender. Quando o ensino e a aprendizagem são entendidos como ações separadas, incorre-se na visão de que ensinar compete ao professor, e aprender ao aluno. Um transmite conteúdos, e o outro os memoriza (ANASTASIOU, 2015; KUBO; BOTOMÉ, 2001).

Contrariamente, no ensino e aprendizagem os objetivos e os métodos de ensino são para favorecer uma aprendizagem, que supera a fixação de conteúdos e evolui para desenvolvimento de outros níveis de cognição, como entender, assimilar, comparar, compreender, criticar, buscar soluções. Nesse movimento, os condicionantes da aprendizagem passam a ser considerados, e novas metodologias de ensino têm sido pesquisadas (ANASTASIOU, 2015).

As metodologias ativas de ensino surgiram na perspectiva de romper com os métodos tradicionais, centrados no professor, e permitir que os discentes construam habilidades e competências, que vão além do domínio técnico-científico, possibilitando que o estudante seja protagonista do seu processo de construção de conhecimento e não meramente um receptor 
de informações. Segundo Araújo (2015), as metodologias ativas de ensino se constituem como caminho para o processo de ensino e aprendizagem e se referem à atividade, enquanto promotora de experiência resultando, então, na aprendizagem. As práticas educativas são mais participativas, dinâmicas, instigadoras, favorecendo a aprendizagem significativa (MELLO; ALVES; LEMOS, 2014; PEREIRA et al., 2018; ROMAN et al., 2017).

Aprendizagem significativa é uma teoria que foi desenvolvida, na década de 1960, pelo psicólogo David Ausubel, nascido nos Estados Unidos e filho de judeus. Para ele, aprender exige um processo de modificação do conhecimento, quando uma nova informação se relaciona com o conhecimento pré-existente e provoca mudanças em suas estruturas cognitivas. Assim, a teoria da aprendizagem significativa procura atribuir significado à realidade do indivíduo, preocupando-se com a compreensão, a transformação, o armazenamento e a utilização das informações envolvidas na aprendizagem. O trabalho central dessa sua teoria está na identificação dos fatores que efetivam e facilitam a aprendizagem, como os conhecimentos prévios (DISTLER, 2015; SANTOS; KAULFUSS, 2015).

Importante descrever que o termo significativo, neste contexto, não é exatamente um assunto que tem importância para o estudante. Na aprendizagem significativa, o conteúdo deve fazer sentido na estrutura cognitiva do aluno, considerando suas ideias, experiências prévias e maturidade intelectual, a partir das quais o novo assunto fará sentido e poderá ser explicado por ele com as próprias palavras. $\mathrm{Na}$ aprendizagem significativa, o aprendiz não é um receptor passivo, ele constrói e produz seu conhecimento (SOUSA et al., 2015).

Na formação de profissionais de saúdee, consequentemente, nas práticas educativas reproduzidas por eles, há um forte histórico de metodologias tradicionais com influência do modelo de saúde e de formação biomédica e hospitalocêntrica, com o currículo flexneriano, que separa ciclo básico de ensino e de clínica, teoria e prática. No contexto atual se tem questionado a necessidade de mudanças, que superem o estilo ultrapassado e descomprometido de ensino em saúde e formem profissionais crítico-reflexivos para o atendimento das necessidades da população (ROMAN et al., 2017).

As metodologias ativas de ensino e a teoria da aprendizagem significativa são convergentes, pois ambas deslocam o protagonismo da aprendizagem ao estudante, valorizando e propiciando a aprendizagem significativa, duradoura, crítica e reflexiva. Ainda, no ensino em saúde, permite romper a dicotomia teoria e prática, articulando os saberes com a realidade (DANTAS, 2018; HONORATO; DIAS; DIAS, 2018; SOUSA et al., 2015; ROMAN et al., 2017).

Este trabalho tem por objetivo analisar uma prática educativa, segundo a teoria da aprendizagem significativa, sobre metodologias ativas no ensino em saúde, realizada com mestrandos do Programa de Pós-graduação Strictu Sensu Ensino em Saúde - Mestrado Profissional, da Universidade Estadual de Mato Grosso do Sul (PPGES/UEMS), ano letivo 2019.

\section{Material e Métodos}

A prática educativa objeto do estudo foi fruto de uma atividade realizada em uma disciplina do mestrado profissional de Ensino em Saúde, da Universidade Estadual de Mato Grosso do Sul. A atividade consistiu no desenvolvimento de processo educativo com vistas a abordar o tema Ensino em Saúde, na perspectiva de Aprendizagem significativa, segundo os pressupostos do teórico David Ausubel. A pretensão era que os mestrandos vivenciassem o planejamento, a implementação e a análise do processo educativo, considerando o posicionamento teórico assumido.

$\mathrm{Na}$ fase do planejamento, o grupo composto por cinco discentes, todos graduados em Enfermagem, decidiu por recursos de comunicação à distância, grupo em aplicativo de mensagens WhatsApp ${ }^{\circledR}$ e Google Documentos ${ }^{\circledR}$, para elaboração compartilhada do plano de aula. O período disponibilizado no cronograma da disciplina para atividade de dispersão foi utilizado para os encontros presenciais.

A implementação ocorreu em 4 horas-aula, seguindo o plano de aula elaborado. Os discentes, que conduziam a atividade educativa, revezavam-se entre mediação e relatoria das falas dos participantes em diário de campo. A prática educativa foi iniciada com o convite para a confecção de uma "colcha de retalhos". Os participantes foram instruídos a construírem desenhos em folhas de papel, que expressassem algum tipo de experiência prévia, que tenham tido com o uso de metodologias ativas no ensino em algum momento de suas vidas. Em seguida, os discentes foram chamados a verbalizar as experiências retratadas, enquanto dispunham os desenhos no tecido da colcha.

O segundo momento da implementação foi a problematização da temática metodologia ativa, em que os mediadores dispararam perguntas referentes à importância do uso de metodologias ativas, e se favoreciam a aprendizagem. No terceiro momento, a partir do que foi discutido sobre metodologias ativas no processo de ensino e aprendizagem, iniciou-se a avaliação formativa com a construção coletiva do mapa conceitual sobre metodologias ativas. O quarto momento foi a apresentação da teoria da aprendizagem significativa por meio de um cordel elaborado pelo grupo.

A análise da prática educativa foi realizada a partir de percepções dos mediadores e das críticas dos docentes. O processo educativo propiciou o desenvolvimento da "colcha de retalhos", dos relatos das experiências e do mapa conceitual. Esses produtos educacionais serão objeto de análise de conteúdo, e segundo a teoria da aprendizagem significativa. 


\section{Resultados e Discussão}

\subsection{O planejamento de um processo educativo com metodologias ativas}

A proposta disparada pelos docentes é em si uma metodologia ativa de ensino e aprendizagem, sendo os discentes protagonistas em toda a ação. O grupo foi composto por cinco bacharéis em Enfermagem, desafiados a mergulharem no campo do ensino em saúde, com a responsabilidade por conduzir atividades que colaborassem não apenas para o próprio conhecimento, mas também para o dos colegas mestrandos.

Com a amplitude do tema "educação em saúde", e considerando o tempo para implementação da atividade educativa, o grupo optou por delimitar o assunto em "uso de metodologias ativas no ensino em saúde", pela sua pertinência na disciplina e com anuência dos docentes.

A atividade deveria ser conduzida segundo a teoria da aprendizagem significativa, que postula sobre novos conhecimentos interagirem com os conhecimentos prévios, de maneira substantiva e não-arbitrária. A substantividade é a capacidade de incorporar o conhecimento novo e expressálo em termos de ideias, evidenciando a compreensão, sem a repetição literal do significado. A não arbitrariedade é a relação de conhecimentos novos com conhecimentos prévios relevantes, chamados de subsunçores. É através dessa relação não arbitrária e substantiva de ideias que o conhecimento prévio vai se modificando e o discente vai obtendo novos significados (SOUSA et al., 2015).

O público, que participou da prática educativa, era constituído pelos 02 docentes da disciplina, e pelos 12 colegas mestrandos, todos profissionais de saúde, sendo 1 fisioterapeuta e 11 enfermeiros. Quanto às Instituições de Ensino Superior dos quais eram provenientes os mestrandos, 02 eram formados na região Norte, 03 no Nordeste, 03 no Centro-Oeste, 02 no Sudeste, 02 no Sul do Brasil. Evidentemente, os participantes possuíam experiências prévias de ambientes formais de educação, assim como alguns teriam experiências de educação com os usuários de saúde.

Com essas informações, os objetivos da prática educativa foram definidos. O objetivo geral era relacionar o conceito e a importância das metodologias ativas no processo de ensino e aprendizagem, de forma significativa. Os objetivos específicos eram: promover junto aos mestrandos uma vivência acerca do processo ensino e aprendizagem; resgatar o conhecimento do vivido/estudado no contexto das metodologias ativas; avaliar a experiência vivenciada pelos mestrandos em relação à abordagem da teoria de aprendizagem significativa de David Ausubel.

Para atender aos objetivos respeitando a teoria da aprendizagem significativa, o grupo entendeu que o início da aula deveria estimular a lembrança dos conhecimentos prévios. Assim, o grupo decidiu pela metodologia, que permite aos atores envolvidos utilizarem do seu potencial e de sua criatividade na construção de uma "colcha de retalhos" para falar de vivências com metodologias ativas de ensino em saúde.

A "colcha de retalhos" que aqui se trata é um dispositivo inspirado no livro infantil Colcha de Retalho, de Conceil Corrêa Silva e Nye Ribeiro (2010), e no filme Colcha de Retalhos (How to make an American quilt, de Jocelyn Moorhouse, EUA, 1995), e que em comum tecem uma colcha juntando pedaços com várias histórias, saberes, desejos e caminhadas que podem transformar o seu eu e transformar o meio ao seu redor.

\subsection{A confecção da colcha de retalhos: subsunçores, troca de saberes e reflexões}

$\mathrm{Na}$ prática educativa estavam presentes quatorze participantes, sendo dois deles docentes. Todos confeccionaram seus retalhos, e ao dispô-los na colcha, explicavam o sentido de seus desenhos. Cada participante, à sua maneira, conseguiu expressar sua vivência com o uso de metodologias ativas no processo de ensino e aprendizagem, o que demonstrou que todos, em algum momento de suas vidas, tiveram uma experiência com a temática abordada.

Os participantes revisitaram as suas memórias e relataram vivências em diferentes espaços de ensino em saúde, na situação de educador ou de educando. As experiências contadas foram como graduandos (3), mestrandos (1), estudantes de especialização (1), docente de graduação (1), docente de ensino técnico profissional de nível médio (1), extensão universitária (1), profissional em serviços de saúde (3), profissional de saúde em escola (2). Outro participante (1) não verbalizou uma situação ou momento específico, mas explicou que o desenho tem dois cenários, um da educação bancária tradicional, e outro da roda de conversa, que é uma das metodologias ativas que desloca a centralidade do saber para todos, e não mais em um professor.

Um participante relatou que o contato com as metodologias ativas foi no PPGES. Três dos que já as vivenciaram anteriormente desenharam experiências, que aconteceram após o ingresso no mestrado, nos quais eles foram os proponentes da metodologia ativa em seu campo de trabalho: (1) um na docência da graduação, (1) um na docência de ensino técnico de nível médio, (1) um como enfermeiro com função técnicoadministrativa em Instituição de Ensino.

Pode-se observar que o PPGES tem exercido influência na aplicação de metodologias ativas de ensino no campo de trabalho dos mestrandos, mais especificamente, nos espaços formais de ensino. Nos relatos de uso de metodologias ativas de ensino em serviços de saúde observou-se ausência do campo hospitalar.

A construção da "colcha de retalhos" despertou algumas reflexões sobre as experiências vividas pelos participantes, como mostram alguns trechos do Diário de Campo (DC):

Participante 1: Conta a história que sua experiência com ensino era com método tradicional, mas teve uma situação 
em que não conseguia entender patologia, e o professor então mudou a estratégia, e criou um game. [...] e se tinha lembrado, é porque teve significado.

Participante 4: Usou vídeos disparadores para problematização [...] o método foi realmente significante, os alunos refletem o perfil de profissional que querem ser.

Participante 7: Explica que o desenho é sobre troca de experiências. Diz que [...] não basta estar em roda [de conversa], tem que fazer parte da roda.

Participante 11: fala que o contato com metodologias ativas foi nas aulas desse mestrado, e que a troca de experiências favorece o aprendizado.

Participante 12: mostra o desenho e fala da importância de conhecer o perfil da população para uma atividade educativa.

A técnica da confecção da "colcha de retalhos" demonstrou ser potencialmente significativa, na medida em que atendeu ao objetivo proposto de resgatar o saber dos discentes sobre metodologias ativas no ensino e aprendizagem, acompanhado de ressignificações, como a troca de experiências e as ponderações sobre o contexto de aplicação.

Pensando a colcha de retalhos como uma estratégia de ensino, se irá ao encontro da releitura que se faz de Paulo Freire, o educando como ativo, sujeito participante e a sala de aula como espaço de diálogo. Pois, por ser desenvolvida por meio de vários retalhos desconexos, diferentes e contraditórios, mas que também se complementam e se conectam, despertando no outro a capacidade de saber ouvir, de aprender com um coletivo, construir e reconstruir possibilidades, tornando significativa a aprendizagem.

Rosito e Silva (2017) descrevem a colcha de retalhos como uma metodologia formativa, que permite trazer à tona possibilidades para pensar, agir e sentir, destacando a importância da voz dada a cada sujeito, como elementos constituintes dentro do processo. Além disso, possibilita a construção e a produção de um conhecimento sobre o desenvolvimento da prática, pois o sujeito ao falar escuta, ao escutar reflete e ao refletir, analisa, realizando uma ação mais reflexiva e consciente, diante de suas escolhas e decisões.

Jogar conteúdos para o educando, fazendo dele um ser passivo na aprendizagem é uma prática de ensino, que não permite aos sujeitos desenvolverem suas potencialidades. Quando suas experiências, suas referências, seus saberes trazidos são valorizados, cada história forma um retalho que, além de servir como base de construção para a produção do conhecimento, desencadeia um processo de autoria e de emancipação do sujeito em seu contexto social, pessoal e profissional (ROSITO; SILVA, 2017).

Amaral (2000), ao fazer uma analogia da colcha de retalhos com o senso comum, mostra que a colcha expressa o saber "banal" ou popular, através da união de vários retalhos cheios de histórias, de vivências, de encontros e de visões de mundo, costuradas manualmente, com paciência, resignação, revolta, dor, compreensão, fé, carinho, raiva e arte. Assim, este saber deixa de ser banal e passa a ser um saber extraordinário, pois o conhecimento que dá luz a essa colcha de retalhos é extremamente significativo, porque é abarrotado de vitalidade, já que brotou de uma relação direta do ser humano com o mundo e com os seus pares.

\subsection{A problematização: escolhas estratégicas do método de ensino-aprendizagem}

Com os subsunçores mobilizados com a colcha de retalhos, a prática educativa foi conduzida para o momento de problematização, em busca de construção de novas significações sobre a temática. A problematização traz os educandos para o protagonismo da aprendizagem, quando vão realizando novas significações. Os mediadores podem interagir com devolutivas, direcionando a ressignificação, pois aprendizagem significativa não necessariamente implica em aprendizagem correta, isto é, o educando pode atribuir significados a um conhecimento prévio, mas estes não serem os aceitos no contexto de um assunto (MOREIRA, 2010).

Os mediadores dispararam a problematização com o resgate do conhecimento prévio compartilhado e com as perguntas instigadoras: as metodologias ativas são importantes no processo de ensino e aprendizagem? Favorecem ou não a aprendizagem? Por que as experiências relatadas foram marcantes?

Mais à vontade, depois da confecção da colcha de retalhos, e com a provocação dos mediadores, as reflexões foram aprofundadas. Os participantes começaram a ponderar entre metodologias ativas e metodologia tradicional, entendida pelos mesmos como aula expositiva. O entendimento era de que a escolha do método de ensino e aprendizagem deve considerar o perfil do público, o objetivo da instrução, a postura do professor, assim como traz as falas registradas no diário de campo (DC):

Entender o perfil da turma é importante, o perfil do aluno, o perfil do professor. [....] Para conduzir método ativo, é preciso ter uma mudança no professor. $\mathrm{O}$ docente tem dificuldade de método ativo [...]. O diferente nem sempre é bom [...]. Tem ensino tradicional que é significativo (DC).

Para efeito dessas reflexões, há autores que preferem o termo estratégias de ensino, pois consideram que o professor deve ser um verdadeiro estrategista ao planejar e conduzir um processo educativo. É preciso visar um objetivo, e explorar os meios mais favoráveis para alcançá-lo. Esses meios compreendem os variados métodos ou técnicas de ensino, que respeitam as condições que favorecem a sua aplicação. Assim, conhecer o público é essencial na escolha da estratégia que propicie a mobilização do pensamento e do aprendizado (ANASTASIOU; ALVES, 2015).

A reflexão do grupo de que o ensino tradicional pode ser significativo é verdadeiro considerando que a aprendizagem é significativa, quando novas informações puderem se relacionar com os subsunçores na estrutura cognitiva da pessoa, gerando assimilações e ressignificações de forma clara e coerente (MOREIRA, 2010; MOREIRA, 2011; PELIZZARI et. al., 2002).

Sendo assim, essa aprendizagem diverge da aprendizagem 
mecânica ou memorística, em que os conteúdos repassados não se relacionam de forma coerente e clara à estrutura cognitiva do sujeito. A aprendizagem mecânica é, geralmente, utilizada com a intenção de armazenar informações para uma certa finalidade, e após utilizadas tendem a ser esquecidas. Apesar das aprendizagens significativa e mecânica serem opostas, essas não constituem uma dicotomia, sendo possível que em um mesmo episódio de ensino aconteçam os dois tipos de aprendizagem, com variação do nível de significação (MOREIRA, 2010; MOREIRA, 2011; PELIZZARI et. al., 2002).

\subsection{Os papéis de educando e educador nas metodologias ativas}

Os participantes demonstraram o entendimento de que, com métodos ativos, o educando é o protagonista pelo próprio aprendizado, devendo assumir uma postura de interesse pela aprendizagem, enquanto o professor facilita e conduz a aprendizagem:

O papel do professor é de facilitador [...]. Na metodologia ativa, a leitura é importante. Se você não ler, fica fora da roda. (DC).

Assim como as metodologias ativas requerem um movimento de busca do estudante, a teoria da aprendizagem significativa postula que deve haver uma predisposição do aluno para aprender. Também é necessário que o conteúdo seja potencialmente significativo (MOREIRA, 2010; MOREIRA, 2011; PELIZZARI et al., 2002).

$\mathrm{O}$ educador que abdica dos métodos tradicionais e passa a utilizar os métodos ativos de ensino, em sua prática, proporciona ao educando e a si mesmo crescimento intelectual, integração e cooperação com todos, estimulando a busca pela construção do conhecimento e a motivação a aprender. Esse profissional atua como um mediador do processo de ensino e quebra a visão tradicional da transferência do conhecimento. Essa forma de ensinar permite ao aluno perceber a realidade em que está encaixado, e por meio das experiências, dos desafios, das situações retiradas do contexto vivido, ele vai construindo o conhecimento atribuindo-o a aprendizagem (TRINDADE; COSTA, 2017).

No ensino ativo, o discente desenvolve a autonomia no processo da aprendizagem, ou seja, aprende a aprender, rege suas próprias leis, desenvolve a sua capacidade críticareflexiva, torna-se capaz de tomar decisões com independência moral e intelectual (TORRES; CARNEIRO; FERNANDES, 2019).

O processo de ensinar, a partir do uso de metodologias ativas, permite tanto ao educador como educando serem partícipes no processo. O educador ao mediar a aprendizagem deve atentar-se para as ações que levem o aluno a trabalhar a autonomia como ação cotidiana, não somente com vistas à produção de um conhecimento, mas também, paralelamente e de modo intrínseco, como viés de desenvolvimento humano e pessoal (TORRES; CARNEIRO; FERNANDES, 2019).

Como o uso das metodologias ativas nas práticas de ensino está intimamente ligada com o protagonismo dos sujeitos, na atividade desenvolvida, em sala de aula, os participantes revisitaram as suas experiências e trouxeram suas reflexões, como as registradas em dois trechos do DC:

começou a usar o método ativo [...] Hoje tem mais significado, dá muito mais certo e $\mathrm{O}$ método ativo permite a reflexão, não ficar apenas na técnica pela técnica.

Corroborando com Paulo Freire, a experiência do vivido se torna a referência para o momento reflexivo da prática é pensando criticamente a prática atual, que se pode melhorar a próxima prática (FREIRE, 1996). Ao fazer essa revisitação se produz uma reflexão sobre a ação passada e se pode transformar as ações futuras, colocando em prova uma nova compreensão do problema, emergindo possibilidades de como fazer ou desenvolver algo.

Nesta lógica de pensamento "freiriano", o profissional ao refletir sua prática deve ser capaz de promover uma ação transformadora sobre seus desejos, vontades e histórias. Segundo Freire (1996, p.39): "o importante é que a reflexão seja um instrumento dinamizador entre teoria e prática". Assim, a metodologia aplicada na colcha de retalhos permitiu aos envolvidos um exercício reflexivo entre o fazer e o pensar, ou seja, pensar para fazer e pensar sobre o que fazer através do resgate das experiências anteriores, produzindo reflexões críticas que, certamente, levarão a transformações de ações futuras no emprego das metodologias ativas.

\subsection{Influências na proposição de metodologias de ensino e aprendizagem}

As decisões relacionadas à aplicação de métodos tradicionais e ativos sofrem influência do contexto e experiências dos educadores. Um dos participantes diz que iniciou o trabalho na docência reproduzindo o método tradicional. A sua reflexão sobre o método levou a buscar outras formas de ensinar e aprender.

Um dos participantes diz que reproduzimos o método tradicional. Começou a usar o método ativo sem perceber. Depois que começou a entender que se era metodologia ativa. Hoje entendo o conceito e significado. Hoje tem mais significado, dá muito mais certo (DC).

Outro participante fala que sentiu dificuldade de usar metodologias ativas nos ambientes de trabalho:

Conta que a formação, a faculdade toda foi com metodologias ativas. Mas depois foi engolido pelo mundo do trabalho, pelo contexto, e teve dificuldades para usar métodos ativos (DC).

Na confecção da colcha de retalhos, e depois no momento de problematização, os ambientes contextualizados para o uso de metodologias ativas no ensino em saúde foram: sala de aula, unidades básicas de saúde, escolas, comunidades. Mesmo que dos 14 participantes, 06 trabalhavam em hospitais, não houve manifestação sobre o uso de metodologias ativas no ensino 
em saúde em ambiente hospitalar.

Sobral e Campos (2012) identificaram que as Instituições de Ensino em Saúde e Assistenciais têm ciência das dificuldades existentes para romper o método tradicional de ensino, bem como da necessidade de mudanças em relação à formação e atuação destes profissionais. Os autores pontuaram, também, que o uso de metodologias ativas parte do interesse do profissional e raramente da instituição. Existem empecilhos como, por exemplo, a falta de investimentos dos órgãos competentes e instituições formadoras, fazendo com que o profissional adapte o uso de metodologias ativas aos recursos disponíveis na realidade em que trabalha.

\subsection{O mapa conceitual como recurso de aprendizagem e avaliação formativa}

O debate sobre metodologias ativas e tradicionais propiciaram reflexões, consensos e ponderações entre os participantes. Os participantes foram então convidados a iniciarem a construção coletiva do mapa conceitual, como estratégia de avaliação formativa.

A avaliação formativa, também chamada de processual, ocorre durante o processo educativo, avaliando-o continuamente para que possa ser melhorado, enquanto acontece. O termo formativo tem o sentido de formação contínua em direção aos objetivos educacionais. Esse tipo de avaliação enfatiza que o educando é responsável pela própria aprendizagem, sendo a autoavaliação fundamental para que combine e articule os recursos cognitivos, culturais e emocionais necessários no aprendizado. O educador desenvolve a escuta e a observação, interagindo com devolutivas (feedback), permitindo ao educando repensar a sua aprendizagem (BOTH; BRANDALISE, 2018; DUARTE,

\section{6; ROMANOWSKI; WACHOWICZ, 2015).}

Nas práticas educativas guiadas pela teoria da aprendizagem significativa, a avaliação da aprendizagem deve ser coerente com a proposta significativa. Logo, a avaliação não pode acontecer somente ao final do processo educativo com caráter de classificação e de confirmação do que foi memorizado, "o que se deve avaliar é compreensão, captação de significados, capacidade de transferência do conhecimento a situações não-conhecidas, não-rotineiras" (MOREIRA, 2010. p.24).

O mapa conceitual é uma técnica não tradicional de ensino e avaliação proposta por Novak e colaboradores estudiosos da teoria de Ausubel, que permite ao educando externalizar os significados que está captando, e de realizar as tarefas da aprendizagem recursivamente, até a significação conforme os objetivos educacionais. Isso acontece por meio de representações gráficas, que mostram a organização e relações entre conceitos. Ao construir o mapa conceitual, o educando mostra a construção do seu conhecimento. A avaliação por mapa conceitual não atribui valor, mas obtém evidências da aprendizagem significativa (AQUINO FILHO; MACHADO; AMARAL, 2015; MORAES; SANTANA; VIANA-BARBOSA, 2011).

Para a construção do mapa conceitual desta prática educativa, o grupo que conduzia a atividade já havia disposto papel pardo sobre todo o quadro branco da sala de aula. Folhas brancas recortadas em retângulos estavam disponíveis para a escrita dos conceitos, que fossem disparados pelos participantes, que seriam organizados e reorganizados sobre o papel pardo com fita crepe. As conexões entre os conceitos foram traçadas com canetão. A Figura 1 mostra o mapa conceitual transcrito para versão digital.

Figura 1 - Mapa conceitual sobre metodologias ativas elaborado pelos mestrandos em Ensino em Saúde, UEMS

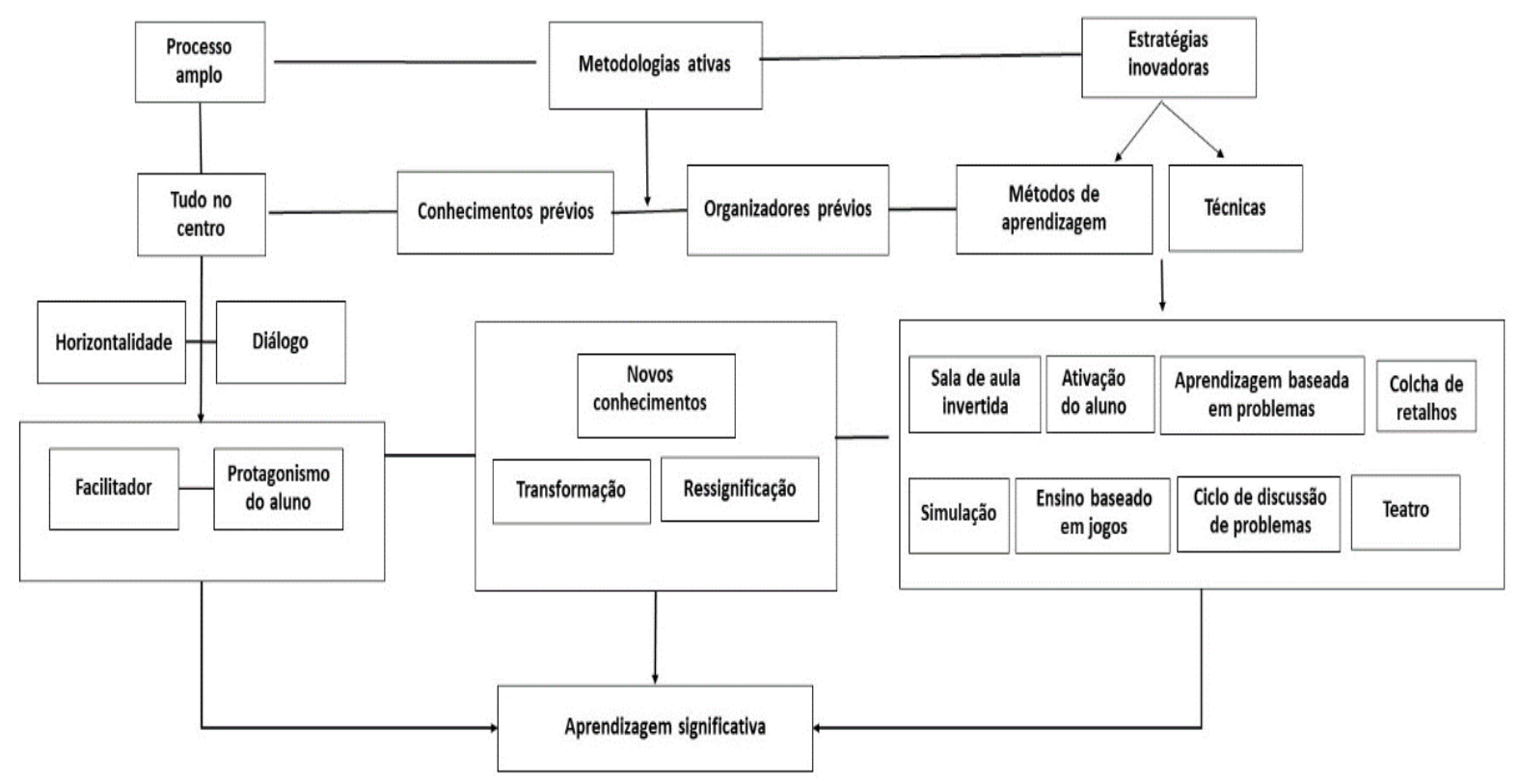

Fonte: Os autores. 
A construção do mapa conceitual iniciou com o tema da aula, metodologias ativas, centralizado na primeira linha imaginária. A construção coletiva enriqueceu as discussões na organização entre as relações dos conceitos. Ao final da construção do mapa, houve a síntese verbal:

As metodologias são um processo amplo, em que alunos são protagonistas do próprio aprendizado, os professores assumem o papel de facilitador desse aprendizado, numa relação dialógica, de horizontalidade, de forma que todos estão no centro da aprendizagem. Para isso, as metodologias ativas valorizam os conhecimentos prévios, ou utilizam organizadores prévios quando os conhecimentos prévios não são resgatados, para que novos conhecimentos promovam transformação e ressignificação. Isso tudo acontece quando estratégias educativas são usadas para decidir os métodos e técnicas de aprendizagem, como: sala de aula invertida, ativação do aluno, aprendizagem baseada em problemas, colcha de retalhos, simulação, ensino baseado em jogos, ciclo de discussão de problemas, teatro. Tudo isso favorece a aprendizagem significativa (DC).

Quando os participantes colocaram o conceito "conhecimentos prévios", os mediadores seguiram com a pergunta provocadora: se por algum motivo não foi identificado conhecimento prévio, como estimular uma aprendizagem significativa? Houve respostas de que em algum nível sempre há uma experiência, se não diretamente sobre um assunto, por assimilações com temas parecidos. Nesse momento, foi apresentado pelos mediadores o conceito “organizadores prévios" proposto por Ausubel, para ser aplicado em situações não-familiares aos estudantes, como comparações ou apresentação de material que os aproximem do objeto de estudo (MOREIRA, 2010).

A síntese verbal enriqueceu o mapa conceitual, uma vez que houve a externalização da compreensão dos significados, permitindo a introdução de um novo conceito relacionado aos já apresentados. Moreira (2010) discorre que a avaliação da aprendizagem significativa precisa ser recursiva, permitindo novas ressignificações, que pode ser facilitada quando educadores e educandos conversam sobre os conceitos e suas relações.

Em busca na Web, foi encontrado mapa conceitual sobre a mesma temática, metodologias ativas (Figura 2). Comparando as Figuras 1 e 2 se pode confirmar que os mapas conceituais evidenciam a particularidade com que cada pessoa ou grupo desenvolve o próprio aprendizado, estabelece conceitos e conexões sobre um assunto, a partir da mobilização de subsunçores.

Figura 2 - Mapa conceitual sobre metodologias ativas

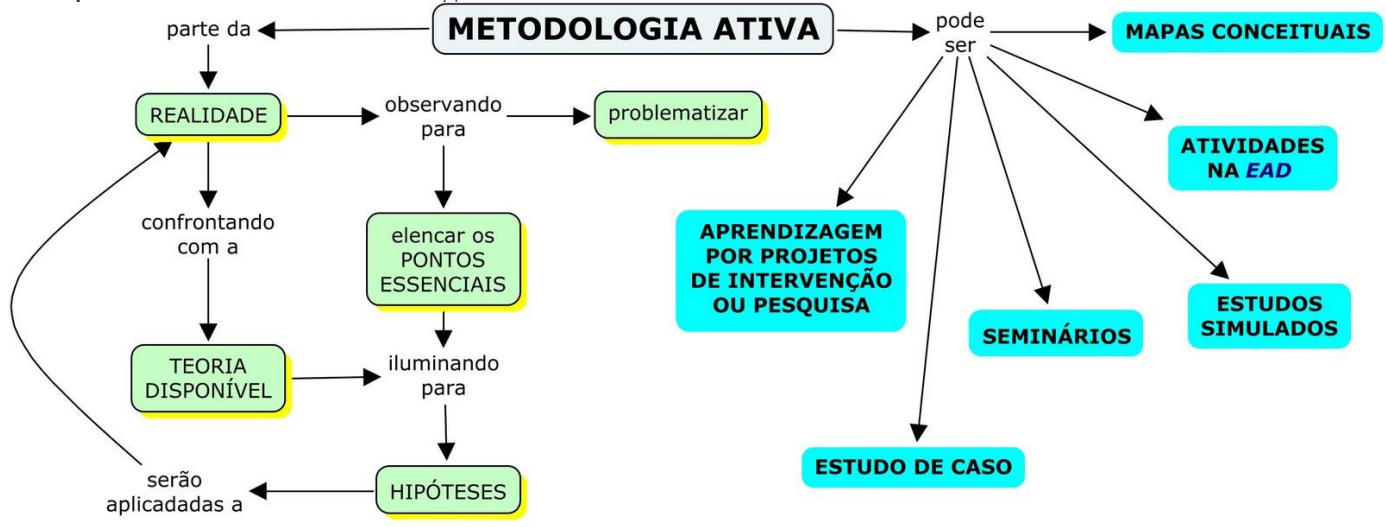

Fonte: Pimentel (2010).

O mapa conceitual como estratégia de metodologia ativa constitui um instrumento que tem a capacidade de revelar significados atribuídos a conceitos e trazer a relação no âmbito de um corpo de conhecimentos. Assim, na estratégia educativa se observou que a construção do mapa conceitual trouxe a representação dos significados dos participantes acerca do tema metodologias ativas de ensino, o que evidencia a aprendizagem significativa do conteúdo por parte dos educandos (MOREIRA, 2012).

\subsection{O cordel: entoação sobre a teoria de Ausubel que embasou o processo educativo}

Durante o quarto momento da prática educativa os participantes foram convidados a retirarem os cordéis, que estavam dispostos na sala de aula, em barbantes e que foram elaborados pelo grupo. O referido cordel foi elaborado de forma a contemplar elementos da teoria da aprendizagem significativa de David Ausubel de forma rimada, dando musicalidade aos versos que traziam estes elementos e, com intuito de exprimir o tema abordado na prática educativa de maneira a despertar o interesse e a atenção dos educandos, além de se tratar de uma ferramenta didática e educativa. Após isto, iniciou-se a entoação do cordel por uma das componentes do grupo como encerramento da prática educativa. Segue o cordel:

\footnotetext{
Aprendizagem Significativa/ DAVID AUSUBEL

Aqui venho dizer que aprender significativamente é trazer tudo aquilo que já temos guardado na mente é ampliar as ideias novas com as já existentes

Multiplicando o conhecimento para guardar na cabecinha da gente.

O processo de aprender é uma grande emoção

Para ele ter sentido temos que fazer reflexão
} 
O professor que nos ensina é também nossa motivação

É o profissional qualificado para criar os momentos com potencial de construção.

Ausubel viveu a prática de ensino arbitrária,

Então resolveu ensiná-la de maneira contrária

O discurso da prática docente deixou de ser indutivo

O ensinar para fazer sentido não pode ser impositivo

Aqui se troca o "sim Senhor" pelo Subsunçor,

Um processo dinâmico em que o conhecimento vai sendo construído.

Muitas formas são tentadas, e algumas são mais especiais, como:

Construir estruturas mentais utilizando como meio mapas conceituais

Aqui venho dizer que para aprender o aluno deve querer

Se mostrar a disposição, e ter bastante empolgação.

E agora pra findar Ausubel mostra que é capaz

Tornar a aprendizagem prazerosa e eficaz.

\section{Conclusão}

Essa prática educativa não teve a pretensão de esgotar o assunto de metodologias ativas de ensino e aprendizagem, mas instigar a curiosidade dos discentes sobre a temática para recorrer a métodos significativos de aprendizagem ao longo da carreira/trabalho/vida.

A colcha de retalhos permitiu ao grupo resgatar as experiências com o uso de metodologias ativas. A identificação dos conhecimentos prévios, ou subsunçores, instigaram a reflexão sobre o uso de metodologias ativas no processo do ensino em saúde, e promoveram uma aprendizagem significativa, conforme a teoria de Ausubel.

A análise do momento de problematização identificou que os participantes compreendem a importância da aplicação das metodologias ativas, no ensino em saúde, e a maioria destes já trabalhou com estas metodologias em seus ambientes de trabalho, mesmo sendo habituados a metodologias de ensino tradicionais desde sua formação profissional.

O mapa conceitual, recurso de aprendizagem e de avaliação formativa, permitiu evidenciar a síntese sobre a temática da aula, com mobilização de significados. Dessa forma, o objetivo geral da prática educativa foi alcançado, de forma que as metodologias ativas foram relacionadas e conceituadas de forma significativa.

A prática educativa mobilizou subsunçores na temática, com problematização, reflexão e ressignificação, tanto nos participantes quanto nos mediadores, de forma horizontal no ensino e aprendizagem, em que quem ensina aprende, e quem aprende também ensina, dialogicamente. Portanto, foi um processo de metodologia ativa de ensino com aprendizagem significativa.

Para os mestrandos, responsáveis pelo processo educativo, desde o planejamento até a avaliação, a experiência de balizar o processo segundo um referencial teórico possibilitou a compreensão que toda proposta educativa carrega concepções em relação a ensinar e aprender. E como essas concepções estavam definidas e ancoradas por um referencial pedagógico, procurou-se organizar o processo conectando coerentemente objetivos educacionais, estratégias/métodos de ensino e avaliação de aprendizagem.

Identifica-se a necessidade de mudanças, por parte das instituições de ensino e docentes, na formação dos profissionais de saúde, com intuito de romper o método tradicional e aderir cada vez mais ao uso de metodologias ativas de ensino, podendo formar profissionais mais críticos, éticos e reflexivos, que atenda realmente a necessidade da população.

\section{Referências}

AMARAL, R.A.P. A "colcha de retalhos": uma metáfora do conhecimento. Rev. Inter Ação, v.25, n.2, p.23-25, 2000. doi: https://doi.org/10.5216/ia.v25i1.1690

ANASTASIOU, L.G.C. Ensinar, aprender, apreender e processos de ensinagem. In: ANASTASIOU, L.G.C.; ALVES, L.P. (Org.). Processos de ensinagem na universidade: pressupostos para as estratégias de trabalho em aula. Joinvile: Univille, 2015. p.17-44

ANASTASIOU, L G.C.; ALVES, L.P. Estratégias de ensinagem. In: ANASTASIOU, L.G.C.; ALVES, L.P. (Org.). Processos de ensinagem na universidade: pressupostos para as estratégias de trabalho em aula. Joinvile: Univille, 2015. p.73-107.

AQUINO FILHO, G.F.; MACHADO, J.T.M.; AMARAL, L.H. Ausubel: aprendizagem significativa e avaliação. Rev. Atlante Cuad. Educ. Desarrollo, 2015. Disponível em: http://www. eumed.net/rev/atlante/2015/10/ausubel.html. Acesso em: 22 set. 2020.

ARAÚJO, J.C.S. Fundamentos da Metodologia de Ensino Ativa. In: REUNIÃO NACIONAL DA ANPED, 37. Florianópolis, 2015, Florianópolis: UFSC, 2015.

BOTH, I.J.; BRANDALISE, M.A.T. Interferência pedagógica na avaliação da aprendizagem no ensino presencial e a distância com o uso de tecnologias. Rev. Ibero-Americana Estud. Educ., v.13, n.2, p.807-821, 2018. doi: https://doi.org/10.21723/riaee. v13.n2.2018.9924

COLCHA de Retalhos. Direção de Jocelyn Moorhouse. EUA: Amblin Entertainment/Universal Pictures, 1995. DVD (116 $\min )$.

DANTAS, F.C. Diretrizes para aprendizagem significativa no ensino da enfermagem: uma contribuição para o cuidado. Niteroi; Escola de Enfermagem Aurora de Afonso Costa, 2018.

DISTLER, R.R. Contribuições de David Ausubel para a intervenção psicopedagógica. Rev. Psicopedag., v.32, n.98, p.191199, 2015.

DUARTE, C.E. Avaliação da aprendizagem escolar: como os professores estão praticando a avaliação na escola. Holos, v.8, p.53-63, 2016. doi: https://doi.org/10.15628/holos.2015.1660

FREIRE, M. Observação, registro e reflexão: instrumentos metodológicos I. São Paulo: Espaço Pedagógico, 1996.

FREIRE, P. Pedagogia da autonomia: saberes necessários à prática educativa. São Paulo: Paz e Terra, 1996.

HONORATO, C.A.; DIAS, K.K.B.; DIAS, K.C.B. Aprendizagem Significativa: uma introdução à teoria. Mediação, v.13, n.1, p.2237, 2018.

KUBO, O. M.; BOTOMÉ, S. P. Ensino-aprendizagem: uma interação entre dois processos comportamentais. Interação Psicol., v.5, 2001. doi: http://dx.doi.org/10.5380/psi.v5i1.3321

MELLO, C.C.B.; ALVES, R.O.; LEMOS, S.M.A. Metodologias de ensino e formação na área da saúde: revisão de literatura. Rev. CEFAC, v.16, n.6, p.2015-2028, 2014. doi: http://dx.doi. org/10.1590/1982-0216201416012.

MORAES, J.U; SANTANA, R.G; VIANA-BARBOSA, C.J. Avaliação baseada na Aprendizagem Significativa por meio de 
Mapas Conceituais. In: ENPEC - ENCONTRO NACIONAL DE PESQUISA EM EDUCAÇÃO EM CIÊNCIAS E I CIEC CONGRESSO IBEROAMERICANO DE INVESTIGACIÓNEN ENSEÑANZA DE LÃS CIÉNCIAS, Campinas: Atas, 2011.

MOREIRA, M.A. A aprendizagem significativa: um conceito subjacente. Aprendiz. Significativa Rev., v.1, n.3, p.25-46, 2011.

MOREIRA, M. A. Mapas conceituais e aprendizagem significativa. 2012. Disponível em: https://www.if.ufrgs. br/ moreira/mapasport.pdf. Acesso em: 25 set. 2020.

MOREIRA, M. A. O que é, afinal, aprendizagem significativa? 2010. Disponível em: moreira.if.ufrgs.br/oqueeafinal.pdf. Acesso em: 22 ago. 2020

PELIZZARI, A. et. al. Teoria da aprendizagem significativa segundo Ausubel. Rev. PEC, v.2, n.1, p.37-42, 2002.

PEREIRA, P.R.B. et al. Metodologias ativas no processo da aprendizagem significativa. Rev. Olhar Cient., v.4, n.1, p. 592616,2018

PIMENTEL, F.S.C. Metodologias Ativas. Educ. Online, 2010. Disponível em: http://fernandoscpimentel.blogspot.com/2010/08/ metodologias-ativas.html. Acesso em: 28 nov. 2020

ROMAN, C. et al. Metodologias ativas de ensino-aprendizagem no processo de ensino em saúde no Brasil: uma revisão narrativa. Clin. Biomed. Res., v.37, n.4, 2017. doi: http://dx.doi. org/10.4322/2357-9730.73911

ROMANOWSKI, J.P.; WACHOWICZ, L. A. Avaliação Formativa no ensino superior: que resistências manifestam os professores e os alunos? In: ANASTASIOU, L.G.C.; ALVES, L.P. (Org.). Processos de ensinagem na universidade: pressupostos para as estratégias de trabalho em aula. Joinvile: Univille, 2015. p. 121-139.

ROSITO, M.M.B; SILVA, M L. "Colcha de Retalhos" e narrativas autobiográficas: um olhar da psicanálise. Rev. Estud. Aplic. Educ., v.2, n.4, 2017. doi: https://doi.org/10.13037/rea-e.vol2n4.4736

SANTOS, S. S.F.; KAULFUSS, M.A.Aprendizagem significativa: conceito historico. Rev. Cient. Eletr. Ciênc. Aplic. FAIT, v.6, 2015. Disponível em: http://fait.revista.inf.br/imagens_arquivos/ arquivos_destaque/yNxLZeJ3NiwvknH_2017-1-21-10-37-9.pdf. Acesso em: 17 out. 2020.

SILVA, C. C; RIBEIRO, N. A colcha de retalhos. São Paulo: Editora do Brasil, 2010.

SOBRAL, F. R.; CAMPOS, C. J. G. Utilização de metodologia ativa no ensino e assistência de enfermagem na produção nacional: revisão integrativa. Rev. Esc. Enferm. USP, v.46, n.1, p.208-218, 2012. doi: http://dx.doi.org/10.1590/S0080-62342012000100028 SOUSA, A. T. O. et al. A utilização da teoria da aprendizagem significativa no ensino da Enfermagem. Rev. Bras. Enferm., v.68, n.4, p.713-722, 2015. doi: http://dx.doi. org/10.1590/0034-7167.2015680420i

TORRES, P. L; CARNEIRO, V. B; FERNANDES, R. T. Autonomia discente na universidade: metodologias ativas e a cibercultura. Rev Teias, v.20, n.56, p.171-187, 2019. doi: https:// doi.org/10.12957/teias.2019.39666

TRINDADE, H.C.S.T; COSTA, V. A. O papel do professor e das metodologias ativas no desenvolvimento de aptidões e conhecimentos necessários para o século XXI. Rev Eletr. Ciênc. Hum., Saúde Tecnol., v.6, n.1, p.28-58, 2017. 